\title{
Urea Intercalated Biochar-a Slow Release Fertilizer Production and Characterisation
}

\author{
A. Manikandan ${ }^{1 *}$ and K. S. Subramanian ${ }^{2}$ \\ 'Research Scholar, Department of Soil Science and Agricultural Chemistry, Tamil Nadu Agricultural University, \\ Coimbatore 641 003, Tamil Nadu; poonamani223@gmail.com \\ 2Professor, Department of Nano Science and Technology, Tamil Nadu Agricultural University, \\ Coimbatore 641 003,Tamil Nadu; kssubra2001@rediffmail.com
}

\begin{abstract}
A laboratory study was undertaken to determine the $\mathrm{N}$ release pattern of Urea Intercalated Biochar derived from Prosopis juliflora. Biochar was produced by pyrolysing the wood cuttings excluding the bark at $350^{\circ} \mathrm{C}$. The resultant biochar was characterized using XRD, FT-IR, Raman Spectroscopy and SEM. After characterization, different forms of nitrogen viz., $\mathrm{NH}_{4^{+}}, \mathrm{NO}_{3}, \mathrm{NH}_{2}$, Combined $\mathrm{NH}_{4^{+}}$and $\mathrm{NO}_{3^{-}}$were loaded at varying concentrations (20-200 mM) and sorption and desorption characteristics were examined. Among the forms tested, urea fortified with biochar showed lower desorption at levels of $\mathrm{N}$ loading concentration. A new biochar based formulation was evolved by intercalating biochar with urea at 1:1 ratio through hydrothermal method. The intercalated urea: biochar (1:1 ratio) fertilizer was characterised using the set of equipments and the total nitrogen was quantified as $30 \%$ as per the EDAX values which closely coincided with analytical values. The retention and release pattern of urea intercalated biochar depicts that the biochar derived PJ is a potential substrate that can be exploited to develop slow release $\mathrm{N}$ fertilizer with higher use efficiency and less environmental harzard.
\end{abstract}

Keywords: Biochar, Pyrolysis, Slow Release Fertilizer, Sorption, Urea.

\section{Introduction}

Nitrogen continues to be the "kingpin" of nutrient kingdom in agroecosystems. Despite several decades of research, it is hardly possible to enhance the use efficiency with fewer percentages from $30 \%$ to $35 \%$ through coating of widely used nitrogenous fertilizer (urea) with neem, tar, starch etc [1]. In addition to the organic substances, inorganic substrates such as zeolite, montmorillonite and halloysite minerals have also been introduced to regulate the release of $\mathrm{N}$ from conventional urea. These minerals are quite useful but their extraction and purification is time consuming and a costly affair [2]. This necessitated searching for an alternate substrate to regulate the release of $\mathrm{N}$ from urea.
Biochar is produced by burning the biomaterials (crop residues and wood wastes) under oxygen limited conditions (pyrolysis) at $350^{\circ} \mathrm{C}$ for 30 minutes and cooling of the substance overnight. Biochar is used as a soil amendment/conditioner to improve physical phenomena [3]. Among the biomaterials, Prosopis juliflora (PJ) wood is known to produce $30 \%$ output [4] besides its use as a fuel wood, fodder, charcoal and timber. The carbon content of $P J$ Biochar is $50-70 \%$ [5]. Biochar is microporous in nature, besides extensive surface area $\left(120 \mathrm{~m}^{2} \mathrm{~g}^{-1}\right)$ that can be exploited for loading of nutrients $[6,7,8,4]$. This study hypothesized that the biochar can be used as a substrate to regulate the adsorption and desorption of pattern of different forms of $\mathrm{N}\left(\mathrm{NH}_{2}-\mathrm{N}\right.$, $\mathrm{NH}_{4^{+}}-\mathrm{N}, \mathrm{NO}_{3^{-}}-\mathrm{N}$, combined $\mathrm{NO}_{3^{-}}-\mathrm{N}, \mathrm{NH}_{4^{+}}-\mathrm{N}$ that

*Corresponding author:

A. Manikandan (poonamani223@gmail.com) 
can serve as a base to develop biochar based slow release fertilizers.

\section{Materials and Methods}

\subsection{Biochar Production}

PJ wood samples were collected at Krishnampathi Lake, Coimbatore $\left(11.0183^{\circ} \mathrm{N}, 76.9725^{\circ} \mathrm{E}\right)$. The wood $(25 \mathrm{~cm})$ without bark was dried at $80^{\circ} \mathrm{C}$ for 48 hours to remove the moisture and exudates. Washed with deionised water 5 times, the chopped woods $(4-5 \mathrm{~cm})$ were dried at $80^{\circ} \mathrm{C}$ for 48 hours and soaked further in dilute Sulphuric Acid $\left(\mathrm{H}_{2} \mathrm{SO}_{4}\right)$ to destroy insects and microorganisms. Thereafter, it was dried and slow pyrolysis was followed at temperature of $350^{\circ} \mathrm{C}$ for 30 mins with resident time of 8 hours. Solid char was rinsed with distilled water 3 times to remove the ash materials and dried. The char was ground in a flour mill and sieved through $0.5 \mathrm{~mm}$. The resultant powder was subjected to physiochemical and structural analysis using standard procedure [9].

\subsection{Nutrient Loading and Sorption Studies}

A gram of biochar was weighed in a centrifuge tube and nitrogen in different forms viz., $\mathrm{NH}_{4^{+}}, \mathrm{NO}_{3^{-}}, \mathrm{NH}_{2^{\prime}}$ Combined $\mathrm{NH}_{4^{+}}$and $\mathrm{NO}_{3^{-}}$were loaded at various concentrations of $\mathrm{N}$ from 20 to $200 \mathrm{mM}$ as indicated in the protocol [10]. The polypropylene tubes were laid horizontally in a mechanical shaker and agitated continuously for $24 \mathrm{~h}$ followed by centrifugation at $5000 \mathrm{rpm}$ for $10 \mathrm{~min}$. The supernatant was decanted and $\mathrm{NH}_{2}-\mathrm{N}$ and $\mathrm{NO}_{3^{-}}-\mathrm{N}$ was determined spectrophotometrically using Nesslers' Reagent and $\mathrm{NH}_{4^{+}}-\mathrm{N}$ was estimated by distillation as suggested in the protocol [11]. The statistical analysis was determined using standard procedures [12].

\subsection{Intercalation of Urea, Biochar and Characterisation}

Urea solution was prepared by mixing by adding deionised $\mathrm{H}_{2} \mathrm{O}$ at $1: 1 \mathrm{w} / \mathrm{v}(10 \mathrm{~g}: 10 \mathrm{~mL})$ ratio and the slurry was heated on a hot plate at $105^{\circ} \mathrm{C}$ with constant stirring till the crystals turned into solution. About $10 \mathrm{~g}$ of biochar was mixed thoroughly with the urea solution. The mixture was dried in a hot air oven at $65^{\circ} \mathrm{C}$ till the moisture is completely exhausted. One gram of adhesive polymer ( $\operatorname{starch}$ ) was added to the mixture and air dried, powdered and used as an urea intercalated biochar fertilizer. The resultant fertilizer product was characterized using Fourier Transform Infrared Spectroscopy (FTIR) in the range of 600 to $4000 \mathrm{~cm}^{-1}$ using Attenuated Total Reflectance (ATR) technique. The FT-IR spectra were detected in a pellet that was prepared by mixing the fertilizer with $\mathrm{KBr}$ at the rate of $0.1 \%$.

In order to confirm the loading of $\mathrm{N}$, the Raman Shift was determined using Raman Spectroscopy (Model R $3000 \mathrm{QE}$ ). About 1-2 grams of intercalated urea-biochar fertilizer was kept in a glass cuvette and the Raman shift was determined at $785 \mathrm{~nm}$ [13]. The fertilizer material was sputter coated with gold before imaging under Scanning Electron Microscope (FEI Quanta 200). About 40-50 $\mu \mathrm{g}$ of fertilizer sample was dusted on the carbon conducting tape. In the sample, Energy Dispersive X ray Spectroscopy (EDS) was done to ascertain the elemental composition. The powder XRD patterns of the biochar and urea impregnated biochar (1:1) were recorded using Bruker D8 Advance Powder X ray Diffractometer, Germany.

\section{Results}

\subsection{Physio-chemical Properties}

The PJ biochar had $86.5 \% \mathrm{C}, 1.56 \% \mathrm{~N}, \mathrm{CN}$ ratio $55: 1, \mathrm{pH}$ 9.16 and EC $0.15 \mathrm{dSm}^{-1}$. The bulk density, particle density and percent pore space registered in the biochar were 0.50 and $0.71 \mathrm{~g} \mathrm{cc}^{-1}$ and $30 \%$, respectively.

\subsection{Nitrogen Loading and Sorption}

The $\mathrm{NH}_{4^{+}}-\mathrm{N}^{-}$and $\mathrm{NO}_{3^{-}}-\mathrm{N}$ contents of biochar loaded with four forms of $\mathrm{N}$ viz., $\mathrm{NH}_{4^{+}}, \mathrm{NO}_{3^{-}}, \mathrm{NH}_{2}$ and Combined $\mathrm{NH}_{4^{+}}$at various concentrations $(20-200 \mathrm{mM})$ were quantified at the equilibrium. The desorbed $\mathrm{NH}_{4^{+}}-\mathrm{N}$ in the solution derived from all the four forms $\mathrm{N}$ showed a linear pattern correspondingly with the concentrations. Among the forms, urea fortified biochar had the lowest desorption values at all the concentrations. In contrast, biochar loaded with ammonium nitrate had the highest $\mathrm{NH}_{4^{+}}-\mathrm{N}$ regardless of concentrations in Figure 1. Biochar fortified with either $\mathrm{NO}_{3^{-}}-\mathrm{N}$ or $\mathrm{NH}_{4^{+}}-\mathrm{N}$ singly had the similar pattern of desorption in Figure 2.

The desorbed $\mathrm{NO}_{3^{-}}-\mathrm{N}$ in the solution derived from various forms $\mathrm{N}$ increased with increasing concentrations. Among the forms, urea fortified biochar had the lowest desorption values at all the concentrations. On the 
other hand, biochar loaded with ammonium nitrate had the highest $\mathrm{NO}_{3^{-}}-\mathrm{N}$ regardless of concentrations. Biochar fortified with either $\mathrm{NO}_{3^{-}}-\mathrm{N}$ or $\mathrm{NH}_{4^{+}}-\mathrm{N}$ singly had the similar pattern of desorption.

\subsection{Characterisation}

Among the forms of N, biochar fortified urea appeared to retain both nitrate and ammonical $\mathrm{N}$ irrespective of various concentrations. Therefore, the characterization was focused only on biochar fortified urea.

The FTIR spectra of PJ biochar and urea impregnated biochar (1:1) fertilizer is shown in Figure 3. The FTIR pattern clearly indicated that the biochar fortified urea had $\mathrm{NH}_{4^{+}}$peaks of wave number at 2086 to $2804 \mathrm{~cm}^{-1}$ that confirms urea hydrolysis and the resultant $\mathrm{NH}_{4^{+}}$being adsorbed on the biochar substrate. The Raman shifts of

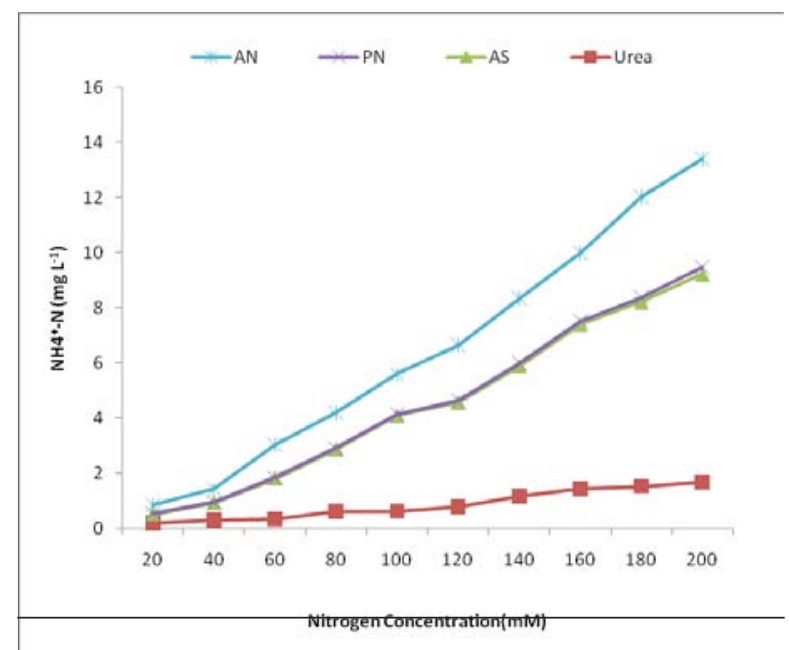

Figure 1. Desorption of $\mathrm{NH}_{4^{+}}-\mathrm{N}$ of different forms of fertilizer source on biochar.

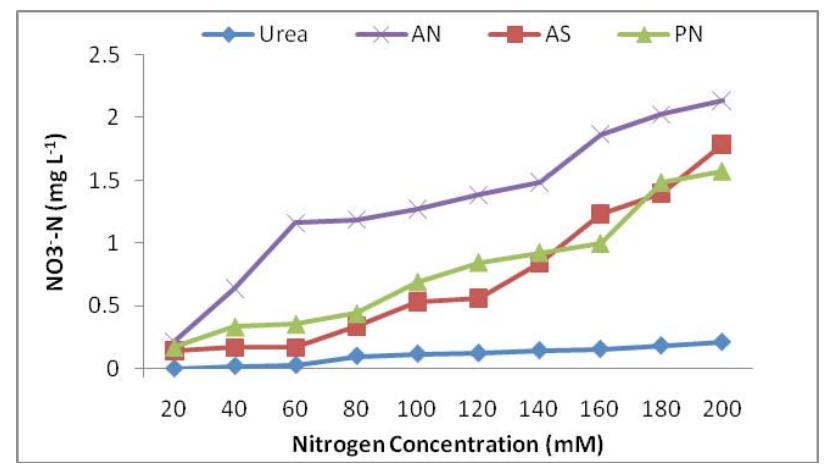

Figure 2. Desorption of $\mathrm{NO}_{3^{-}}-\mathrm{N}$ of different forms of fertilizer source on biochar. biochar and urea impregnated biochar (1:1) are shown in Figure 4 . The data clearly indicated the adsorption of $\mathrm{N}$ that closely coincided at the peaks 1356, 1690 and $1922 \mathrm{~cm}^{-1}$ and confirmed the loading.

The powder X ray Diffraction patterns of PJ biochar and urea impregnated biochar (1:1) fertilizer are depicted in Figure 5. The data revealed that the highly disordered amorphous PJ biochar has changed its structural integrity to crystalline peaks after loading of urea on to biochar. The $2 \theta$ values of $22,25,29,32,36,41,45$ and 49 peaks confirmed $\mathrm{N}$ loading on to the biochar.

The Scanning Electron Micrographs (SEM) with EDS of PJ biochar and urea loaded biochar are shown (Figures $6 \& 7$ ). It showed the disordered carbon and porosity of slow pyrolysed PJ biochar particles. Micropores increased with the combined effect of water and temperature. The pores are scattered in nature and presence on all surface with wide range of size (1.5 to $8 \mu \mathrm{m})$ and shape. Micropores used to improve water and nutrient holding capacity.

Pyrolysed biochar at low temperature might be a suitable adsorbent for controlled/slow release of fertilizer nutrients and which contains carbon and oxygen of more than 98 per cent. After impregnation of urea on biochar, the nitrogen adsorped on micropores was confirmed through EDS. $\sim 30 \%$ of nitrogen present on all places of microporous surface of biochar and internal surface pores were utilised for loading of $\mathrm{N}$ by slow diffusion. As s coating agent, sucrose (10\%) solution were used to keep intact of nitrogen on biochar internal surfaces.

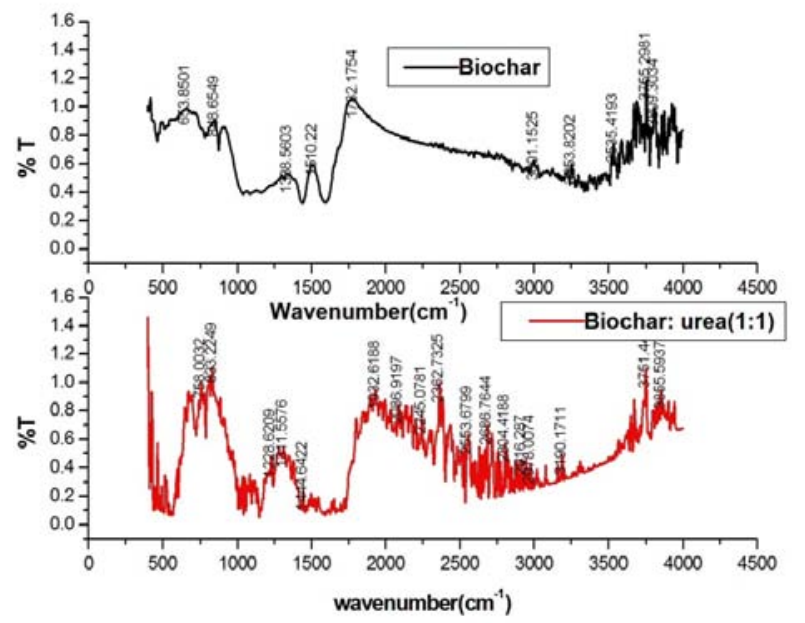

Figure 3. FTIR spectra of biochar and urea loaded biochar (1:1). 

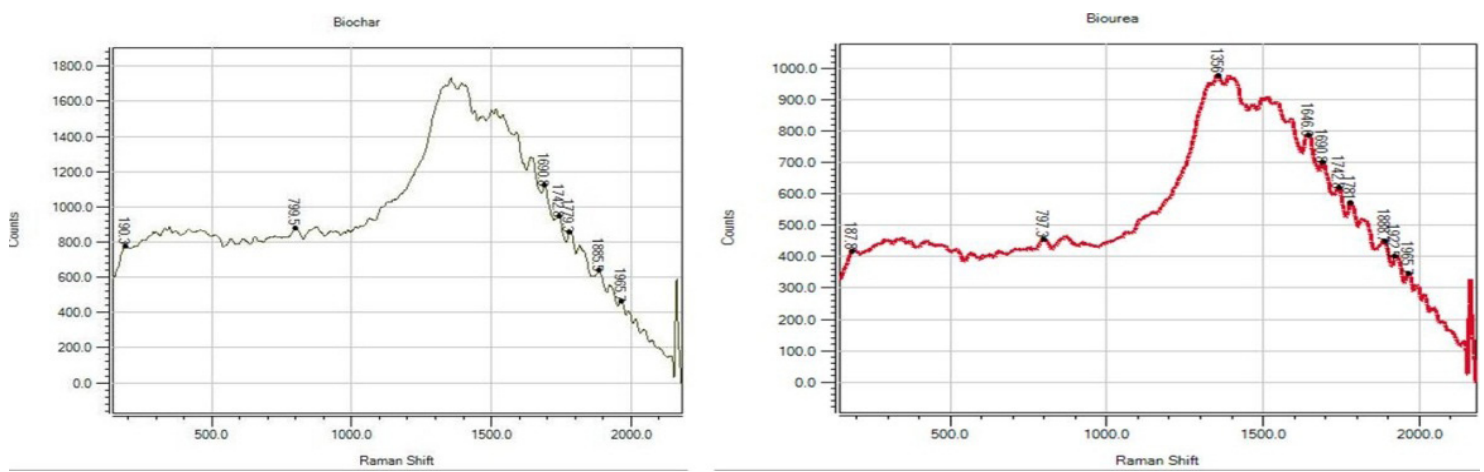

Figure 4. Raman shifts of biochar and urea loaded biochar (1:1).
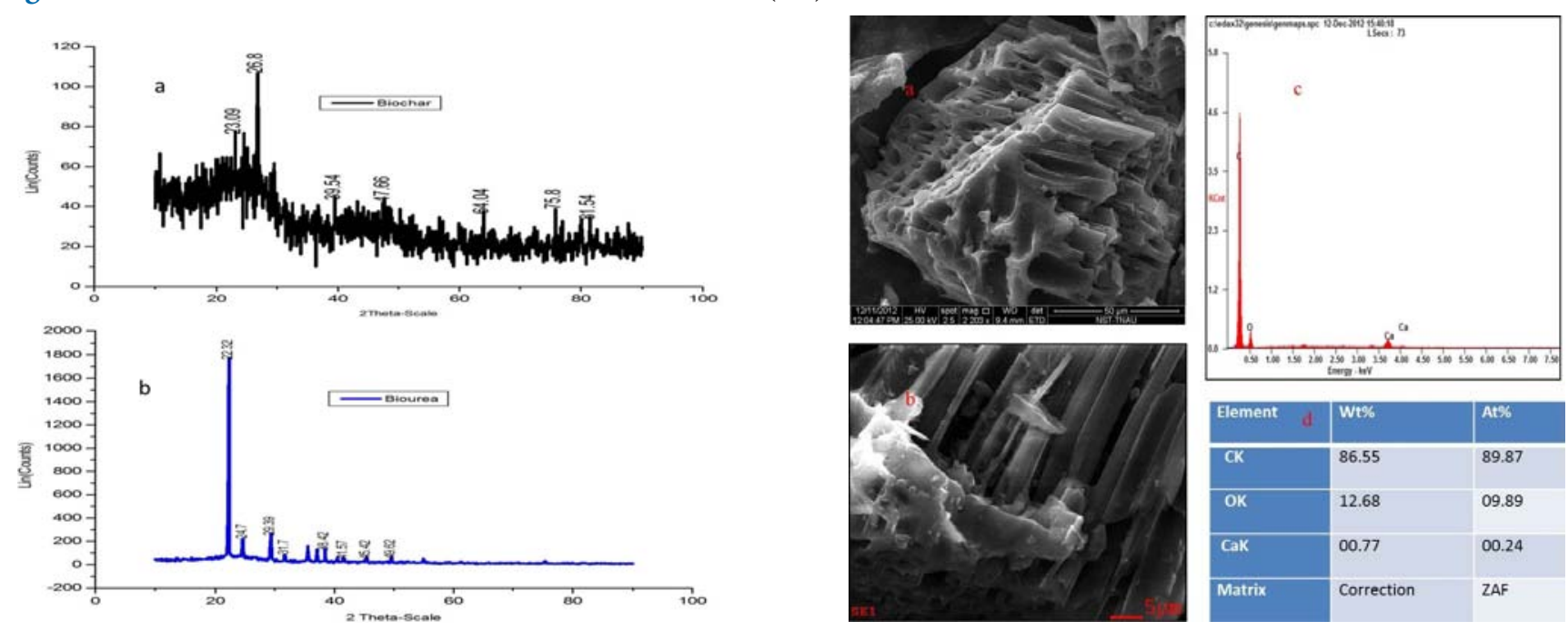

Figure 5. Powder $\mathrm{X}$ ray diffraction patterns of a) biochar and b) urea loaded biochar.

Figure 6. a). Scanning micrograms of PJ biochar b-d). Quantitative composition biochar with EDS.
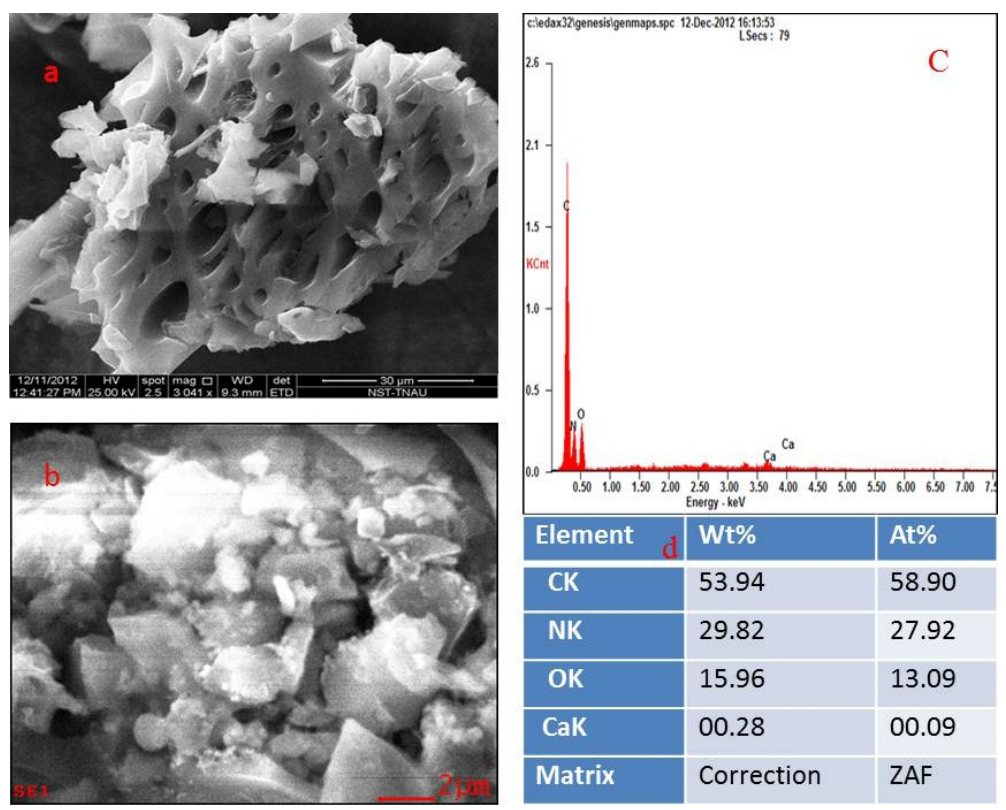

Figure 7. a) Urea impregnated biochar. b-d) confirmation of $\mathrm{N}$ loaded on biochar with EDS. 


\section{Discussion}

Biochar is gaining popularity to use as a substrate to adsorb or desorb nutrients in order to evolve slow release or controlled release of fertilizers by exploiting its extensive surface area. The quality of biochar varied with tree species and PJ has been evaluated as the best and widely used for soil amendments [14]. Adsorption of ammonium ion by coconut shell activated carbon from aqueous solution was reported [15] previously. Initially, the biochar was characterised through EDAX and recorded the highest carbon content of $86 \%$ with $\mathrm{C}: \mathrm{N}$ ratio of 55 and the data closely coincided with earlier reports [14].

Desorption pattern of $\mathrm{N}$ clearly indicated that the biochar fortified with urea had the least and the biochar based urea intercalated had the highest. The data are in conformity with the observations made [16] previously, where it was shown similar desorption pattern for ammonium. It is obvious that least amount of desorption indirectly indicates the retention of $\mathrm{N}$ in the biochar intercalated urea while reverse is true with $\mathrm{NH}_{4^{+}}-\mathrm{N}$. The data support that the biochar-urea is a potential source of slow release fertilizer that is very pertinent to promote $\mathrm{N}$ use efficiency while minimizing the environmental hazard [17].

Since the urea intercalated biochar area had the lowest desorption, this form was studied further for its properties. The biochar intercalated with urea was characterized using FT-IR, Raman Spectroscopy, XRD and besides SEM imaging. The FT-IR results have shown the $\mathrm{NH}_{4^{+}}$ peaks that may be due to the urea hydrolysis and adsorption of resulted $\mathrm{NH}_{4}+$. The findings closely corroborate with other reports wherein the loading of $\mathrm{NH}_{4^{+}}$was detected with the same set of peaks appeared in the same wavelengths [18]. Further, the XRD pattern suggests that the loading of $\mathrm{NH}_{4}+$ shrinks the $2 \theta$ of biochar intercalated urea from 23 to 22 . This process had changed the state of the substrate from amorphous to crystalline confirmed both by XRD and SEM imaging [19-22].

\section{Conclusions}

This research findings depicts that the biochar derived PJ is a potential substrate that can be exploited to develop slow release $\mathrm{N}$ fertilizer with higher use efficiency and less environmental harzard.

\section{Acknowledgement}

This Ph.D. Research work was awarded by University Grants Commission (UGC) under the title of Smart delivery of $\mathrm{N}$ in Plant system through Nano fertilizers. The authors are grateful to authorities of UGC, NewDelhi, Tamil Nadu Agricultural University and Bharathiar University, Coimbatore for their support and assistance provided during the course of investigation.

\section{References}

1. Smith J D, and Harrison H C (1991). Evaluation of polymers for controlled release properties when incorporated with nitrogen fertilizer solutions, Communications in Soil Science and Plant Analysis, vol 22(5-6), 559-573.

2. Pereira E L, Minussi F B et al. (2012). Urea-montmorillolite extruded nanocomposites: a novel slow release material, Journal of Agricultural and Food Chemistry, vol 60(21), 5273-5278.

3. Coumaravel K, Santhi R et al. (2011). Biochar-a promising soil additive-a review, Agricultural Reviews, vol 32(2), 134-139.

4. Shenbagavalli S, and Mahimairaja S (2012). Characterization and effect of biochar on nitrogen and carbon dynamics in soil, International journal of advanced biological research, vol 2(2), 249-255.

5. Lehmann J (2007). A handful of carbon, Nature, vol 447(7141), 143-144.

6. Clough T J, and Condron L M (2010). Biochar and the nitrogen cycle: introduction, Journal of Environmental Quality, vol 39(4), 1218-1223.

7. Spokas K A, and Novak J M et al. (2012). Biochar's role as an alternative $\mathrm{N}$ fertilizer: ammonia capture, Plant and Soil, vol 350(1-2), 35-42.

8. Toosi A T, and Clough T J et al. (2012). A wood based low temperature biochar captures $\mathrm{NH}_{3}-\mathrm{N}$ generated from ruminant urine $\mathrm{N}$ retaining its bioavailability, Plant and Soil, vol 353(1-2), 73-84.

9. Nelson D W, and Sommers L E (1982). Total carbon, organic carbon and organic matter. Page A L, Miller R H et al. (Eds.), Methods of soil Analysis, Part 2, Chemical and Microbial Properties, American Society of Agronomy Inc. and Soil Science Society of America Inc., 539-579.

10. Mizuta K, Matsumoto T et al. (2004). Removal of nitratenitrogen from drinking water using bamboo powder charcoal, Bioresource Technology, vol 95(3), 255-257.

11. Onken A B, and Sunderman H D (1977). Colorimetric determinations of exchangeable ammonium, urea, nitrate, and nitrite in a single soil extract, Agronomy Journal, vol 69(1), 49-53. 
12. Panse V G, and Sukhatme P V (1985). Statistical Methods for Agricultural Workers, ICAR Publications, New Delhi, $1-21$.

13. Wang Y, Alsmeyer D et al. (1990). Raman spectroscopy of carbon materials: structural basis of observed spectra, Chemistry of Materials, vol 2(5), 557-563.

14. Shenbagavalli S, and Mahimairaja S (2012). Production and characterization of biochar from different biological wastes, International journal of plant, animal and environmental science, vol 1(1), 197-201.

15. Boopathy R, Karthikeyan S et al. (2013). Adsorption of ammonium ion by coconut shell-activated carbon from aqueous solution: kinetic, isotherm, and thermodynamic studies, Environmental Science and Pollution Research, vol 20(1), 533-542.

16. Hollister C C (2011). Ammonium, Nitrate and Phosphate sorption to water-rinsed and non-rinsed biochars, M.Sc. Thesis, Cornell University, 1-54.
17. Day D, Evans R et al. (2005). Economical CO2, SOx, and NOx capture from fossil-fuel utilization with combined renewable hydrogen production and large-scale carbon sequestration, Energy, vol 30(14), 2558-2579.

18. Narten A H (1970). Diffraction pattern and structure of aqueous ammonium halide solutions, The Journal of Physical Chemistry, vol 74(4), 765-768.

19. Bapat H D, and Manahan S E (1998). Chemchar gasification of hazardous wastes and mixed wastes on a biochar matrix, Abstract Papers American Chemical Soceity, vol 215(8), 571.

20. Bridgwater A V (1994). Catalysis in thermal biomass conversion, Applied Catalysis A: General, vol 116(1-2), 5-47.

21. Sen H S (2009). Soil and water management research- a relook vis-a-vis ecology and climate change, Journal of the Indian Society of Soil Science, vol 57(4), 398-411.

22. Sohi S P, Krull E et al. (2010). A review of biochar and its use and function in soil, Advances in Agronomy, vol 105, 47-82. 